RESEARCH NOTE

\section{BCG and Praziquantel for Schistosomiasis Treatment}

\section{Luciana de Gouvêa Viana ${ }^{+}$, Yerkes Pereira e Silva, Maria Mônica de Aguiar Garcia, Márcia Nogueira Amorim, Naftale Katz, Ana Lúcia Teles Rabello}

Laboratório de Esquistossomose, Centro de Pesquisas René Rachou-FIOCRUZ, Av. Augusto de Lima 1715, 30190-002 Belo Horizonte, MG, Brasil

Key words: Schistosoma mansoni - BCG praziquantel

Prior study has suggested that praziquantel could be used in lower doses, one-third than the conventional, when associated to BCG in non reactors patients to PPD (N Nohmi et al. 1993, IV International Symposium on Schistosomiasis, $\mathrm{p}$. 165). In schistosomiasis, a higher degree of protective immunity was obtained when BCG was used in combination with a non-living vaccine of schistosomula (SL James et al. 1988 J Immunol 140: 2753) or paramyosin (TP Flanigan et al. 1989 J Clin Invest 83: 1010). Mices immunized with F$\mathrm{T}$ schistosomula (frozen-thawed schistosomula) and BCG presented a high degree of protection against cercariae challenge and their peritoneal macrophages showed augmented schistosomulicidal activity and increased TNF- $\alpha$ and IL-2 production (Y Keisari et al. 1993 Immunobiol 188: 446-459). In the present study, we investigated the interference of the immunogenicity of BCG in the therapeutical efficacy of praziquantel in patients infected with Schistosoma mansoni.

A population of $41 \mathrm{~S}$. mansoni infected students from Sabará, in the State of Minas Gerais, Brazil, was selected by Kato-Katz stool examination (N Katz et al. 1972 Rev Inst Med Trop São Paulo 14: 337-340). They comprised students of both sexes (52.4\% of males, $47.6 \%$ of females), from 12 to 22 years old (age mean: $15.12 \pm 2.43$ ), with the intestinal form of the parasitosis and having 12 to 2232 eggs of $S$. mansoni per gram of feces (epg output mean: 374.16 per gram of feces). All students were tested with five UT of tuberculin purified protein derivated (PPD - Fundação Ataulpho de Paiva, São Paulo, Brasil) and after $72 \mathrm{hr}$ they returned for test reading. Students were considered reactor if presented an induration larger than or equal to five $\mathrm{mm}$. Patients were paired by age, sex and eggs of $S$. mansoni per gram of feces, and divided in three groups: (1) 14 PPD non reactor patients, vaccinated with one dose of intradermic BCG (Fundação Ataulpho de Paiva, São Paulo, Brasil) and treated with $20 \mathrm{mg} / \mathrm{kg}$ of body weight of praziquantel 15 days after; (2) 15 PPD non reactor patients, non vaccinated and treated with praziquantel $20 \mathrm{mg} / \mathrm{kg}$ of body weight; (3) $12 \mathrm{PPD}$ non reactor patients, treated with $60 \mathrm{mg} / \mathrm{kg}$ of body weight of praziquantel. The volunteers were submitted to the study after signed consent form from their parents in which the project and the procedures were described. Four months after BCG vaccination the Mantoux test was repeated and all children became PPD reactors.

Drugs were administered under supervision. The assessment of therapeutic efficacy was based on three consecutive daily stool examinations, two slides from each sample of feces, applying the Kato-Katz quantitative technique six months after treatment. Patients were considered cured when no S. mansoni eggs were detected in serial stool examinations.

Statistical analysis was performed using Epi Info 5.0 software (USD, Inc., Stone Mountain, Georgia). Anova or Kruskal-Wallis analysis were applied depending on Bartlett's test for homogeneity of variance.

It was observed a cure rate of $33.3 \%(4 / 12)$ in group (1) and 58.3\% (7/12) in group (2). In group (3), the cure rate was $90.0 \%(9 / 10)$. No statistical significant difference has been observed between groups (1) and (2) $(\mathrm{p}=0.90)$, but the cure achieved in group (3) was statistically different from that observed for groups treated with $20 \mathrm{mg} / \mathrm{kg}$ of body weight $(\mathrm{p}=0.01)$.

In conclusion, BCG vaccination did not increase drug efficiency of low dose therapeutical scheme of praziquantel in schistosomiasis mansoni human infection.

Acknowledgments: to Mr Wilson Dias for his assistance in the "Gabriela Leite Araújo" School. To the Municipal Health Secretary of Belo Horizonte and MERCK $^{\circledR}$ for supplying PPD and praziquantel, respectively. 
636 BCG and Praziquantel for Schistosomiasis Treatment - LG Viana et al. 